\title{
Redes de cuidado: \\ enfrentamento da Covid-19 nas religiões afro-brasileiras
}

Care networks: coping with Covid-19 pandemic in Afro-Brazilian religions

Daniela Calvo*

doi) $\underline{\text { https://doi.org/10.29327/256659.12.1-8 }}$

\begin{abstract}
Resumo
Os membros das religiões afro-brasileiras reagiram de forma imediata e quase unânime à difusão da Covid-19 no Brasil, seguindo as orientações da Organização Mundial da Saúde. Suas estratégias se desenvolveram para enfrentar as diferentes necessidades de seus membros e da população que se apresentaram durante a crise (sanitária e socioeconômica). Intensificaram as comunicações por meio das redes sociais e da internet, ampliaram suas ações sociais nas áreas em que são inseridos e realizaram rituais e rezas para pedir proteção, cura e a expulsão da Covid-19 da Terra. Aceitação e valorização da ciência inserem-se numa racionalidade médica não exclusiva, baseada na cosmovisão e no modo de existência que são transmitidos e mantidos vivos nos terreiros.
\end{abstract}

Palavras-chave: Covid-19. Saúde. Religiões afro-brasileiras. Pandemia. Cuidado.

\begin{abstract}
Members of Afro-Brazilian religions reacted immediately and almost unanimously to the spread of Covid-19 in Brazil, following the guidelines of the World Health Organization (WHO). Their strategies developed to face the different needs of their members and the population, that appeared during the crisis (sanitary and socioeconomic). They intensified communications through social networks and the Internet, expanded their social actions in the areas in which they are inserted and performed rituals and prayers in order to ask for protection, healing and expulsion of Covid-19 fromthe Earth. Acceptance and enhancement of science are part of a non-exclusive medical rationality, based on the cosmovision and on the mode of existence which are transmitted and kept alive in the terreiros.
\end{abstract}

Keywords: Covid-19. Health. Afro-Brazilian religions. Pandemic. Care.

\section{Introdução}

Quando a imprensa brasileira, a partir do dia 11 de março de 2020, passou a noticiar que a Organização Mundial da Saúde (OMS) decretou o risco de pandemia do novo coronavírus (SARS-CoV-2) e quando os primeiros casos de foram registrados no Brasil, houve a reação imediata de muitas lideranças das

\footnotetext{
* Doutora em Ciências Sociais pela Universidade do Estado do Rio de Janeiro (UERJ). E-mail: dnlclv7@gmail.com.
} 
religiões afro-brasileiras, que divulgaram e adoptaram as medidas de prevenção recomendadas pela OMS.

Em 13 de março, a Rede Nacional de Religiões Afro-Brasileiras e Saúde (RENAFRO Saúde) ${ }^{1}$ já estava divulgando notícias sobre a difusão da Covid-19 no Brasil e as recomendações do Ministério da Saúde de adiar eventos com aglomerações de pessoas, e o 17 de março veio comunicar a suspensão de suas atividades e solicitar a prevenção, o autocuidado, a responsabilidade e a solidariedade para proteger a si mesmo, a própria família e a comunidade. Numa comunicação em sua página de Facebook ${ }^{2}$ que data 16 de março, aFederação das Religiões Afro-Brasileiras(AFROBRAS) solicitou todos os responsáveis por templos religiosos para suspender suas atividades religiosas, em especial, as festas para os orixás eas sessões de umbanda, e para evitar aglomerações.

Desde então, vários pais e mães de santo e adeptos das religiões afrobrasileiras de todo o país começaram divulgar, mediante as redes sociais, sua decisão de cancelar as atividades do calendário litúrgico em seu terreiro, informar e orientar a população sobre as medidas para evitar o contágio. Essas postagens, que continuaram sendo replicadas, obtiveram um grande número de curtidas e comentários, em sua maioria, afirmando a importância de preservar a vida por meio do isolamento social e assumindo comportamentos responsáveis.

Numa primeira fase, as lideranças e os adeptos das religiões afrobrasileiras (sobretudos aqueles que trabalham na área de saúde) construíram uma intensa rede de comunicações pautadas nas informações e nas orientações da OMS e das autoridades de saúde, na medida em que, ao evoluir da crise (que se ampliou da esfera sanitária àquelas econômicas, sociais e políticas), outras iniciativas foram tomadas e os terreiros se tornaram centros de redes de diálogos, relações e cuidados mirados a enfrentar as dificuldades de seus membros, das comunidades em que estão inseridos e da população em geral. Medidas sanitárias, ações sociais, práticas tradicionais de cura e ritos religiosos se entrelaçam, motivam e ressignificam uns aos outros.

Objetivo deste trabalho é analisar as preocupações, os discursos e as ações com que, nos terreiros das religiões afro-brasileiras, se reagiu ao avanço da Covid-19 no Brasil, explorando sua articulação com a visão de mundo e o modo de existência que são transmitidos e mantidos vivos nos terreiros. Emprego como ferramentas de pesquisa as redes sociais, as conversas em grupos de WhatsApp 
de que participo, publicações, artigos, áudios, vídeos e videoconferências divulgados nas redes sociais de redes de terreiros, terreiros, pais e mães de santo e membros das religiões afro-brasileiras do país.

\section{Do lado da ciência para cuidar da saúde}

Marcando sua posição "do lado da ciência" e a responsabilidade de cada um na prevenção do contágio, muitas lideranças e muitos adeptos das religiões afro-brasileiras estão seguindo e recomendando o isolamento social, as práticas de higiene pessoal, um estilo de vida e uma alimentação saudáveis, aconselhando o uso do aplicativo CORONAVIRUS SUS, informando sobre o avanço da epidemia nos diferentes estados e cidades e divulgando notícias sobre a pandemia, as medidas de prevenção, as formas de tratamento e as vacinas da Covid-19.

Figura 1:Recomendação a respeitar as medidas de proteção da Covid-19 pelos 1ideres dos Fórum Mulheres e Axé e do FórumHomens de Axéda RENAFRO Saúde

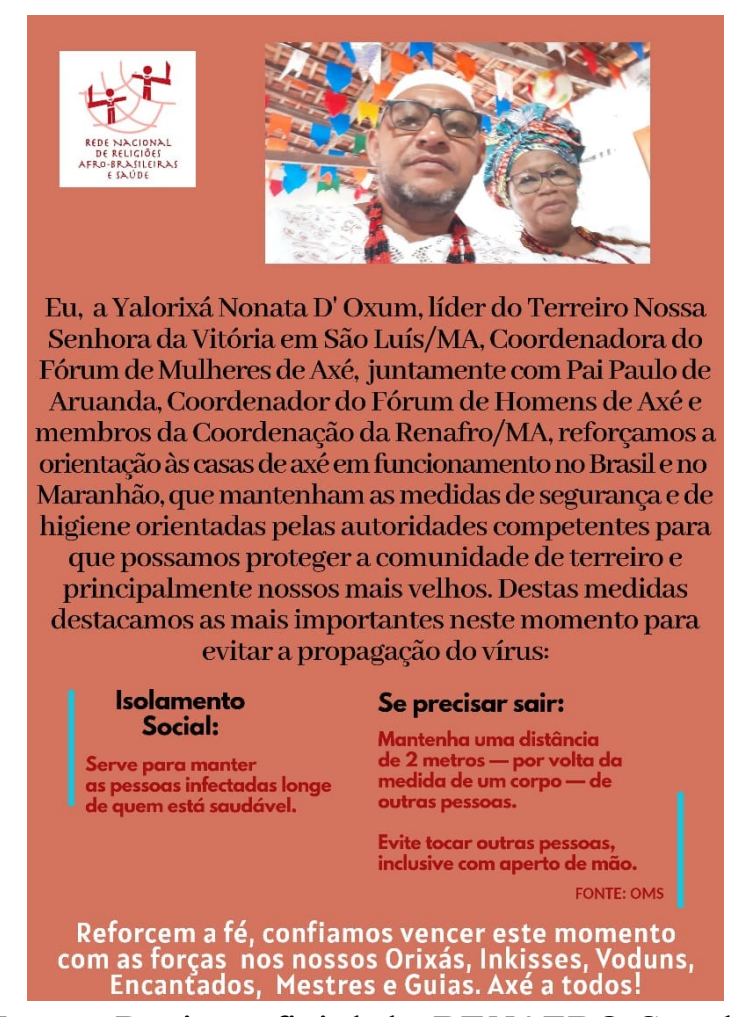

Fonte: Pagina oficial da RENAFRO Saúde ${ }^{3}$

Observo que práticas de autocuidado de herança africana, como tomar banho ao voltar da rua, lavar as mãos, manter o ambiente limpo e privilegiar uma alimentação saudável,fazem parte do cotidiano dos terreiros das religiões afro-brasileiras, como ressaltado por Nunes (2009). 
Em particular, a alimentação, baseada na tradição africana, resulta balanceada e completa do ponto de vista nutricional (Nunes, 2009); seu compartilhamento e sua distribuição (entre os seres humanos, com os orixás, os antepassados e os demais seres espirituais) são valoresfundamentais das religiões de matriz africana, manifestos em todas as ocasiões de festa e de reunião. A comida, desde a escravidão, mesmo em situações de escassez, nunca cessou de ser compartilhada com os membros da comunidade, os necessitados, os orixás e os antepassados, já que se acredita que o axé (a força sagrada que está na base da vida) para poder crescer, deve circular e que o ato de comer juntos ou de comer a comida oferecida por alguém crie e reforce as relações de familiaridade e de aliança.

Nos terreiros, a centralidade dos valores ligados à comida se sobressai também nas ações sociais, na educação alimentar,na distribuição das cestas básicas à população carente, e nas reivindicações de "soberania alimentar."Segundo İyá Dolores -ìyálàse ${ }^{4}$ do Àse Idasilệde, no Rio de Janeiro -a "soberania alimentar" nos terreiros de candomblé representa uma continuidade com a tradição dos próprios antepassados, que plantavam os vegetais e criavam os animais para comerem, e um direito que deve ser reconhecido.

O discurso de Baba Diba de Iyemonja, Coordenador Nacional da RENAFRO Saúde5, ao mesmo tempo, marca a importância de proteger a si mesmo, a própria família e toda a população por meio do isolamento social, e representa um ato político de denúncia e resistência ao extermínio de negros e pobres, que se manifesta também na vulnerabilidade social e na violência estrutural que leva a uma alta percentagem de mortes por Covid-19 entre os negros. ${ }^{6}$

Segundo Baba Diba, prevenir o contágio é também uma forma de proteger as pessoas mais vulneráveis (idosos, crianças, diabéticos, hipertensos, pessoas com problemas respiratórios ou com deficiência imunitária) e uma forma de resistência à "vulnerabilidade social imposta pelo racismo que estrutura nosso Brasil". Observo que, contrapondo-se aos protocolos criados para priorizar leitos nas Unidades de Terapia Intensiva (UTI's) em caso de lotação (na base da expectativa de vida do paciente, deixando, portanto, as pessoas mais idosas e mais vulneráveis no final da fila) ${ }^{7}$, as medidas de prevenção e cuidado promovidas nos terreiros visam proteger sobretudo os mais frágeis e afirmam a importância dos anciãos na cultura tradicional africana, sendo transmissores de memórias e sabedoria. 
No site do Fórum De Segurança Alimentar e Nutricional dos Povos Tradicionais de Matriz Africana (FONSANPOTMA), 8 há um artigo dedicado ao cuidado dos mais velhos, no qual a Dra. Kota Mulanji, coordenadora, sublinhou que "Os mais velhos são para nós os guardiões do conhecimento da vida. Os anciões são o verdadeiro foco de perigo neste período de crise", convidando as pessoas a cuidarem deles: 1) pedimos que nossos mais velhos não sejam expostos, é a hora de oferecer de ir ao mercado, nos lugares que eles precisam. 2) Agora não pode deixá-los sozinhos, traga livros, os distraia e sobretudo faça uma escala de conversação. 3) Quem os visita deve pedir bênção batendo cabeça no chão e não pegando ou beijando a mão, explicar o porquê. 4) Se está faltando o álcool gel, o providencie com informações sobre como usá-lo. 5) Os faça tomar as vacinas para as outras gripes para evitar confusão. 6) Muita água para eles. A RENAFRO Saúde publicou em sua página de Facebook também artigos que denunciam o aumento das desigualdades raciais e sociais durante a pandemia; oferece assistência para o auxílio emergencial e outros beneficios econômicos e organiza coletas de alimentos e de produtos de higiene para serem distribuídos aos necessitados.

Muitas lideranças de terreiros reagiram também ao aumento de problemas psicológicos e emocionais durante a pandemia, já que o medo do contágio ou de perder familiares e amigos, o isolamento social, as incertezas e a precarização de diferentes aspectos da vida (como o trabalho e a situação econômica) e os conflitos familiares se apresentaram ou aumentaram a vida de muitas pessoas. Sacerdotes oferecem sua disponibilidade para conversar e confortar, ou ajuda espiritual à distância; psicólogos de diferentes terreiros e redes de terreiros estão à disposição para ajuda psicológica, por telefone ou videochamada, e as pessoas trocam mensagens e postagens de apoio, afeto, esperança, suporte emocional e disponibilidade de ajuda em caso de necessidade.

Observo que, nas religiões afro-brasileiras, o equilíbrio psicológico é considerado um aspecto fundamental da saúde e do bem-estar do ser humano e objeto de cuidados cotidianos e rituais. De fato, como observado em Calvo (2019), a parte mais importante e mais sagrada do ser humano é oori, a cabeça, que representa a essência da personalidade, a base da percepção, da razão, de pensamentos e sentimentos e do destino, e o elo com o(s) próprio(s) orixá(s). O orí é objeto de rituais, rezas e oferendas voltados para a manutenção da saúde ou que fazem parte do processo iniciático. 


\section{Rezas e rituais online}

Durante a pandemia, diferentes lideranças das religiões de matriz africana marcaram horários para rezarem, ou em videoconferência,a fim de pedir aos orixás proteção, saúde e uma saída rápida da pandemia, e de trazer conforto a quem estava em isolamento social, afastado de seu terreiro. São invocados vários orixás, em particular Ọbalúaié/Omulu/Sakpata/Nsumbu - associado a São Lázaro ou São Roque - que tem, ao mesmo tempo, o domínio sobre a varíola, as epidemias e as doenças contagiosas e da cura, da vida e da morte, e é considerado "o médico dos pobres". Ele, portanto, tem também o poder sobre a Covid-19 epede-se a ele que proteja do vírus e o afaste da Terra.

Figura 2: Convocação para rezar e pedir juntos proteção da Covid-19

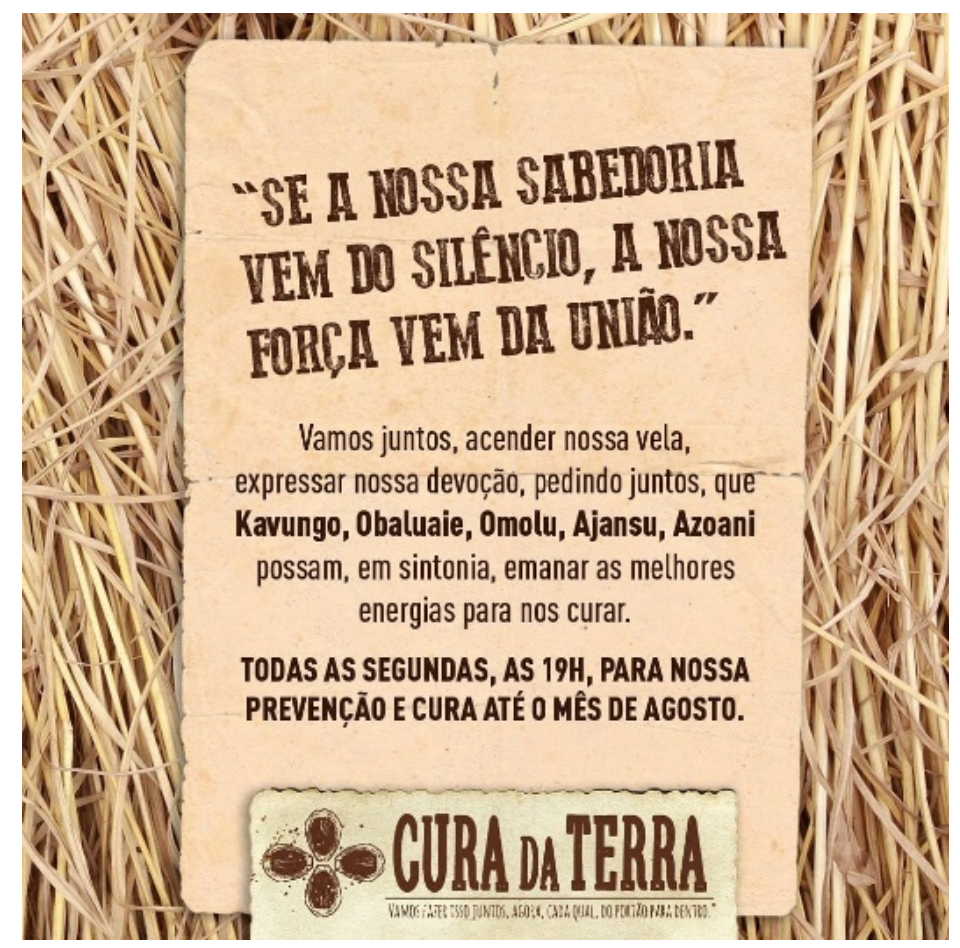

Fonte: Fanpage oficial do Terreiro Tumba Junsara ${ }^{9}$

Como relata um artigo do Correio, ${ }^{10}$ Mãe Mariah de Oxum do terreiro Raiz de Airá, no Recôncavo Baiano, afirmou que "Omolu está sendo convocado 24 horas por dia pelo nosso povo de santo. Toda segunda-feira colocamos muito doburu, ${ }^{11}$ pedindo sempre a ele misericórdia e compaixão, não somente para nós, mas para o mundo inteiro."

Em setembro de 2020, diversos terreiros de Salvador organizaram um cortejo com a estátua de Ọbalúaié, que saiu do Pelourinho e percorreu diferentes bairros da cidade, para encerrar com o oferecimento de alimentos à população 
em situação de rua na região do Largo dos Mares. De acordo com os organizadores, a ação foi um "clamado com fé, por proteção, saúde, cura, paz e esperançadiante da pandemia do coronavirus." 12 Os organizadores ressaltaram também que, por causa da pandemia, evitaram criar aglomerações durante o cortejo, de que participaram somente membros do grupo organizador. Nas redes sociais circularam diferentes vídeos desse cortejo, incluído um em que uma menina vestida de branco incorporou o balúaié durante a procissão, recebeu a pipoca e abençoou as pessoas.

Figura 3. Cortejo com imagem de Omolu em Salvador

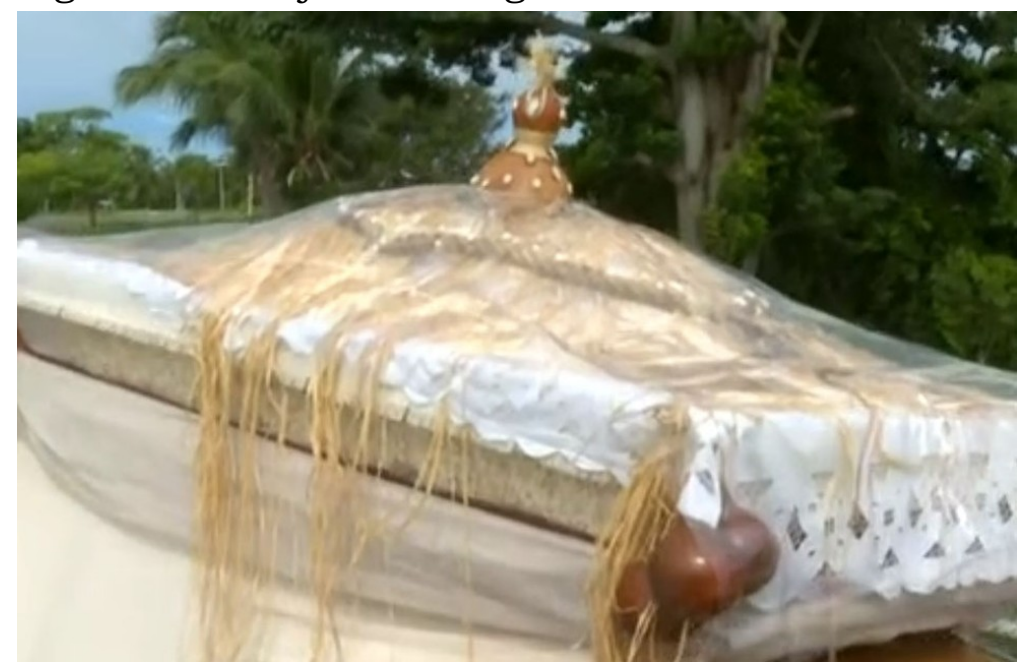

Fonte: Jornal O Globo ${ }^{13}$

Outros orixás que são frequentemente invocados durante a pandemia são Òsányìn, orixádas folhas medicinais, para que ajude os médicos a encontrarem logo uma cura e uma vacina;Oyá, orixádos ventos e das tempestades, para que libere a Terra da Covid-19; Oxum, orixá das águas doces, para que limpe a Terra do vírus; Obatalá, o grande orixá do pano branco que molda os seres humanos, para que traga calma e paz e, junto a Yemanjá (a grande mãe, orixá do mar, é a dona do orí, como seu esposo Obatalá), para que cuide da saúde mental das pessoas.

As celebrações anuais para os orixás foram canceladas ou realizadas de forma reduzida (limitando-se à louvação e às oferendas para os orixás e evitando a festa pública) e restrita a poucas pessoas (muitas vezes, somente aquelas que vivem no terreiro). Todavia, muitas dessas celebrações criam uma reunião de pen-samentos e, em alguns casos, conexões e participações virtuais. Por exemplo, Mãe Wanda de Omulu, do Ilè İyá Mí Òsún Mùiywá, no Rio de Janeiro, ${ }^{14}$ reza "do portão para dentro" todos os dias, às 10 h e às $19 \mathrm{~h}$, em conexão com casas de 
axé da Bahia, de Goiás e Pernambuco. A Casa de Òsùmàrède Salvador realiza as celebrações do calendário litúrgico de portas fechadas, anunciando-as em sua página de Facebook e pedindo que quem queira lhes comunique seus pedidos para que possam rezar aos orixás também em seu nome. Na mesma página de Facebook, ${ }^{15}$ a Casa de Òsùmàrè publicou o vídeo da fogueira de Xangô, acesa em junho em ocasião da sua festa.

\section{Ações de apoio à população}

Durante a pandemia, as comunidades das religiões afro-brasileiras não só continuaram suas ações de apoio à população, mas intensificaram-nas para oferecer sua contribuição numa situação que agravou os problemas já existentes e criou novos. Desde o começo da pandemia, os terreiros reforçarame ampliaram as ações de distribuição de cestas básicas,às quais foram adicionados também produtos de higiene, em muitos casos, colaborando com outros agentes sociais, tais como o Movimento dos Trabalhadores Rurais Sem Terra (MST) e associações de favelas e periferias urbanas. As costureiras dos terreiros passaram a produzir máscaras para distribui-las aos hospitais e à população. Por exemplo, na página de Facebook da Casa de Òsùmàrè ${ }^{16} \mathrm{de}$ Salvador, um vídeo mostra que as costureiras do terreiro converteram sua atividade, passando da produção de vestidos e adereços rituais à confecção de máscaras para os médicos e os enfermeiros dos hospitais da região e, depois, também para a população.

Figura 4. Alimentos, produtos de higiene e máscaras prontos para distribuição no Ilê Omolu e Oxum (Rio de Janeiro).

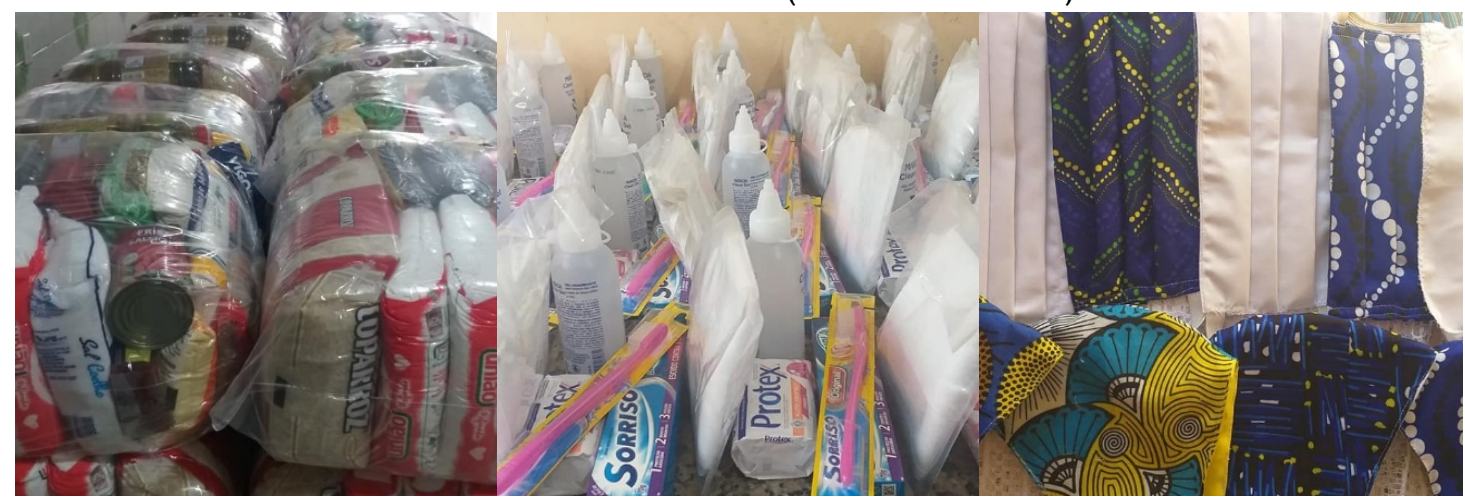

Fonte: Perfil de Facebook de Nilce Naira ${ }^{17}$

Os advogados de diferentes terreiros e associações de terreiros ${ }^{18}$ ativaram um serviço de atendimento sobre os procedimentos para obter as ajudas econômicas do Estado. Durante a pandemia, se multiplicaram também os seminários e as discussões online sobre assuntos religiosos, a pandemia, a saúde, o racismo, 
a intolerância religiosa, a educação, a violência doméstica e contra as mulheres e a população LGBT+, com o intento declarado de não só debater e informar sobre questões consideradas importantes (muitas dos quais faziam já parte da agenda política e social de muitos dos terreiros), mas também de manter as relações e um sentido de comunidade. Na cena pública, se reivindicou também o direito que as pessoas do candomblé mortas por Covid-19 recebam um enterro de acordo com seus valores tradicionais. ${ }^{19}$

As preocupações das lideranças dos terreiros com a preservação da saúde e da vida, não somente de suas comunidades, mas do país e do ecossistema mundial, baseiam-se em seus valores de solidariedade e caridade, na ideia de interconexão entre as pessoas (expressa no conceito bantu de Ubuntu) e numa concepção de "pessoa relacional" (Calvo, 2019), inserida numa malha de relações e de fluxos vitais que conectam os diferentes componentes da sociedade e do cosmo. Portanto, entre as duas possibilidades apontadas por Judith Butler ${ }^{20}$ relativas à possibilidade de a pandemia mudar a sociedade - que se dá ou pela criação de fronteiras (internas e externas) ou pelo reconhecimento da interdependência global - o povo de santo escolheu a segunda.

\section{Cuidado com a saúde do planeta}

O cuidado com a saúde das pessoas está pari-passu com a saúde do planeta e de seu ecossistema.

Os discursos de muitos ecologistas e intelectuais ${ }^{21}$ em prol de uma mudança na economia e na relação com o meio ambiente e a interpretação da Covid19 como consequência da exploração e degradação dos ecossistemas se refletem nas falas das lideranças dos terreiros, de cujas agendas fazem parte há muitos anos ações ecológicas de preservação da natureza.

Como ressaltado em Calvo e Monteiro (2020), no candomblé se atribui um caráter sagrado à natureza e a todos os seres: em sua ontologia, todos os seresse formaram a partir de um processo de subdivisão e molarização de axé, a força sagrada que flui do Ser Supremo, Olódùmarè. O equilíbrio de forças no universo e a circulação do axésão indispensáveis para a continuação da vida e para a saúde de todos os seres, que estão interligados mediante fluxos vitais.

A natureza é transmissora de vida através da alimentação e dos elementos empregados para o culto e os diferentes rituais, e o lugar onde se entra em con- 
tato com as forças sagradas. Portanto, é importante que seja preservada e respeitada a fim de manter (e transmitir) sua força.

Pai Leandro de Xangô, zelador do Centro de Umbanda Jequiriça de Sultão das Matas, ${ }^{22}$ interpretou a pandemia como uma possibilidade de análise e de transformação, sublinhando que:

Vejo o momento que estamos vivendo como uma grande oportunidade de melhoria. Vez ou outra na história, essas coisas acontecem quando há uma disparidade entre o avanço tecnológico e o avanço moral. Quando o homem esquece de valores importantes como Deus, espiritualidade, família, solidariedade e amor, vez por outra surge uma situação como essa, ao meu ver, para fazer o homem se refrear (Pai Leandro de Xangô).

Em suas postagens na página de Facebook do terreiro,23 Pai Silvanilton Encarnação da Mata do Ilé Òsùmàrè Aràká Àse Ògòdó, conhecido como Casa de Òsùmàrè, em Salvador, solicitou os cuidados para conter o contágio por Covid-19 como "verdadeiros gestos de amor e responsabilidade social" e afirmou que:

Nossa confiança no amparo espiritual não pode justificar que descuidemos de nós mesmos, daqueles que amamos, nem do ambiente que habitamos. [...] Somos todos integrantes da mesma humanidade e coabitantes do planeta que nos acolhe. Aproveitemos este desafio para sermos mais humildes diante da natureza e mais generosos com os seres que nos rodeiam. (Pai Silvanilton Encarnação da Mata).

Em suas ações em prol da preservação e do respeito do ambiente, os membros das religiões de matriz africana dialogaram também com representantes quilombolas e com as lideranças indigenas, visando construir uma frente comum para combater a espoliação da natureza no país, sobretudo quando, desde meados de 2020, a emergência ambiental se manifestou de forma dramática com os incêndios no Pantanal. Observo que, nas religiões de matriz africana, a saúde da natureza é também indispensável para a saúde humana, já que:

no candomblé sobressai um pensamento ecológico e relacional do organismo-no-seu-entorno, que fundamenta a perspectiva do habitar o mundo proposta por Ingold $(2000,2008,2012)$, uma antropologia através de linhas de vida, de linhas de crescimento, como um processo em aberto dentro de um campo contínuo de relações, a que participam seres humanos e não-humanos24. (Calvo, 2019, p. 204). 
As malhas de relações e de fluxos vitais de que o ser humano faz parte (incluindo os outros seres humanos e os seres da natureza, os antepassados, os orixás e os demais seres espirituais) afetam seu equilibrio, sua saúde e seu bemestar e podem influenciar a realização de seu destino. Os seres humanos existem somente como parte de um destino comum com outros humanos e com os nãohumanos (seres da natureza, seres espirituais e forças).Sàlámì e Ribeiro (2015) salientam que:

toda pessoa é, em si, um microcosmo inserido num universo dinâmico. Mais fácil é intuir do que alcançar por vias racionais a enorme complexidade do jogo de forças biológicas, sociais, econômicas e politicas, continuamente carregadas de axé, cuja qualidade e cuja quantidade podem variar. E de fato variam (Sàlámì; Ribeiro 2015, p. 148).

Segundo Bastide (1993), "precisa procurar a chave da realidade individual no conjunto das relações, que ligam o homem aos diferentes princípios constitutivos do Cosmo e ao conjunto das relações sociais (incluídos, claro, aqueles que ele nutre com os Mortos [e com diferentes seres espirituais])" (Bastide, 1993, p. 40). E, de acordo com Ribeiro (1996, p. 18),o universo é caracterizado por "correspondências, analogias e interações, ao qual o homem e todos os demais seres constituem uma única rede de força”.

\section{Considerações finais}

O enfrentamento da crise gerada pela difusão da Covid-19 no Brasil confirmou o papel dos terreiros das religiões afro-brasileiras como agentes promotores da saúde e da vida. Integrando as interpretações e os tratamentos da biomedicina à sua racionalidade médica, as lideranças das religiões afro-brasileiras se serviram de diferentes estratégias para cuidar de si, da própria família, de suas comunidades e do planeta.

De fato, o cuidado da saúde (entendida como imbricação dos aspectos físicos, psicológicos, sociais e espirituais) é central nas religiões afro-brasileiras, que atuam práticas de cura (em que conhecimentos de medicina tradicional se combinam com aspectos rituais e sagrados) e diferentes ações em prol da saúde de seus membros e da sociedade em que estão inseridos ${ }^{25}$ (incluindo campanhas de informação sobre saúde, alimentação, educação, luta à intolerância religiosa e ao racismo, colaboração com o SUS, assistência médica e legal à população, distri- 
buição de cestas básicas). Como sustenta Rabelo (2014), no candomblé, o cuidado é o elemento central de uma ética que se constrói de forma tácita mediante práticas, sensibilidades e engajamentos com o outro.

Enraizadas em uma e em um modo de existência que foram mantidos vivos nos terreiros, as medidas de cuidado da saúde adotadas durante a pandemia mostram também a grande capacidade de adaptação e criatividade que permitiu que as religiões afro-brasileiras sobrevivessem ao longo da história e superassem diferentes situações e crises, como ressaltado por Bastide (1995). Por exemplo, durante a pandemia, Omolu adicionou a seus poderes aquele sobre a Covid-19 e, para sustentarem o isolamento social, as comunidades das religiões afrobrasileiras reforçaram e inventaram novas formas de manter conexões de cuidado e de afeto, de rezar e celebrar juntos os orixás.

\section{Referências bibliográficas}

https://www.nordesteusou.com.br/noticias/imagem-de-omolu-ganha-as-ruasde-salvador-em-clamor-por-cura-e-saude-diante-da-covid-19/.Acesso em 30/09/2020.

BARIFOUSE, Rafael. 'Escolhemos quem terá mais chances': a dificil decisão de quem terá acesso a UTI com saúde em colapso. BBC News Brasil. São Paulo, 19 de maio de 2020. Disponivel em: https://www.bbc.com/portuguese/brasil52717 493. Acesso em 15 de fevereiro de 2021.

BASTIDE, Roger. Le príncipe d'individuation (contribution à une philosophie africaine). In: La notion de personne en Afrique Noire. Colloques Internationaux du C.N.R.S. 544 (1973). Paris: L'Harmattan, 1993.pp. 33-44.

BASTIDE, Roger. Les religions africaines au Brésil. Paris: Presses Universitaires de France, 1995.

BUTLER, Judith. Judith Butler sobre a Covid-19: O capitalismo tem seus limites. Trad. de Artur Renzo. Blog da Boitempo. 20 de março de 2020. Disponivel em: https://blogdaboitempo.com.br/2020/03/20/judith-butler-sobre-o-covid-19-ocapitalismo-tem-seus-limites / ?fbclid=IwAR3sKyOxuFi6RMXYO-KK-

vMvt_smG0CY4L3gut9xCRidADRU80Dw6UuYx9w.Acesso em 07 de maio de 2020.

CALVO, Daniela. 'They agreed to kill us, we agreed not to die': Acts of love and resistance to confront Covid-19 by Afro-Brazilian religions members. Collecting COVID-19. A crowd-sourced digital ethnography of the COVID-19 Pandemic. UCL Centre for Digital Anthropology, 2020. Disponivel em: https://anthrocovid. $\mathrm{com} / 2020 / 06 / 05 /$ they-agreed-to-kill-us-we-agreed-not-to-die-acts-of-love-andresistance-to-confront-covid-19-by-members-of-afro-brazilian-religions /. 
CALVO, Daniela. Cuidar da saúde com a força vital da natureza: tratamentos terá-pêuticos no candomblé. 2019. Tese (Doutorado em Ciências Sociais). Rio de Janeiro: Universidade do Estado de Rio de Janeiro, 2019.

CALVO, Daniela; MONTEIRO, Marcelo Dos Santos. A sacralidade da natureza e a sacralização do espaço no candomblé. Revista Senso. Dossiê Espaço Sagrado. Belo Horizonte: Grupo Senso,n. 16, maio-junho de2020.Disponivel em: https://revista senso.com.br/zrs-edicao-16/a-sacralidade-da-natureza-e-a-sacralizacao-doespaco-no-candomble/. Acesso em 10 de fevereiro de 2021.

FORTUNA, Maria. Mãe de santo Wanda d'Omolú afirma: 'Essa doença vai demorarmuito a passar'. O Globo. Rio de Janeiro, 08 de abril de 2020. Disponivel em: https://oglobo.globo.com/cultura/mae-de-santo-wanda-domolu-afirma-essadoenca-vai-demorar-muito-passar-1-24359233. Acesso em 13 de maio de 2020.

GOLDMAN, Márcio. Formas do Saber e Modos do Ser. Observações sobre Multiplicidade e Ontologia no Candomblé. Religião e Sociedade. Rio de Janeiro: ISER,vol. 25, n. 2, 2005.pp. 102-120.

GOMBERG, Estélio. Hospital de Orixás: encontros terapêuticos em um terreiro de candomblé. Salvador: EDUFBA, 2011.

GRAGNANI, Juliana. Por que o coronavírus mata mais as pessoas negras e pobres no Brasil e no mundo. BBC News Brasil. Londres, 12 de julho de 2020. Disponível em: https://www.bbc.com/portuguese/brasil-53338421. Acesso em 30 de setembro de 2020.

HORTÉLIO, Marina. Associação pede proibição de cremação de seguidores do Candomblé. Correio. Salvador, 03 de abril de 2020. Disponivel em:https://www.correio24horas.com.br/noticia/nid/associacao-pede-proibicaode-cremacao-de-seguidores-docandomble/?utm_source=correio24h_share_facebook\&fbclid=IwAR0 PB9V_s6zIOgtJD2GrYQkAmp_KVzyl_KOxMjP2bghhadYkj2kddts9zTc.Acessoem 11 de maio de 2020.

INGOLD, Tim. The perception of the environment. London: Routledge, 2000.

INGOLD, Tim.Trazendo as coisas de volta à vida: emaranhados criativos num mundo de materiais.Horizontes Antropológicos. Porto Alegre: UFRGS, ano 18, n. 37, janeiro-julho de 2012.pp. 25-44.

INGOLD, Tim. Tres en uno: cómo disolver las distinciones entre mente, cuerpo y cultura. In: SÁNCHEZ-CRIADO, Tomás (org.). Tecnogénesis. La construcción técnica de las ecologias humanas. vol. 2. Madrid: AIBR, 2008.pp. 01-33.

LOYOLA, Maria Andréa. Médicos e curandeiros: conflito social e saúde. Rio de Janeiro: Difel, 1983.

LUZ, Madel T. Cultura Contemporânea e Medicinas Alternativas: Novos Paradigmas em Saúde no Fim do Século XX. Physis: Revista de Saúde Coletiva. Rio de Janeiro: UERJ, n. 15 (Suplemento), 2005.pp. 145-176.

LYRIO, Alexandre. Em isolamento, devotos do Candomblé evocam orixá da cura. Correio. Salvador, 11 de abril de 2020. Disponivel em: https://www.correio24horas.com.br/noticia/nid/em-isolamento-devotos-do- 
candomble-evocam-orixa-da-

cu-

ra/?utm_source=correio24h_share_facebook\&fbclid=IwAR1BALjLAQUgw9OOPDR WYDXHLbyKxWYIZ1rSk3EyRQFNWE5XLdat_bGvLo8. Acesso em 13 de maio de 2020.

NUNES, José Mauro Gonçalves. A Herança Africana do Auto-Cuidado: Saberes e Práticas Tradicionais dos Cuidados ao Corpo. In: MANDARINO, Ana Cristina de Souza; GOMBERG, Estélio (org.). Leituras afro-brasileiras: territórios, religiosidades e saúdes. Salvador: Editora UFS; EDUFBA, 2009.pp. 329-336.

RABELO, Miriam C. M. Enredos, Feituras e Modos de Cuidado. Dimensões da Vida e da Convivência no Candomblé. Salvador: EDUFBA, 2014.

REDAÇÃO NES. Imagem de Omolu ganha as ruas de Salvador em clamor por cura e Saúde diante da Covid-19. Nordesteeusou. Salvador, 2 de junho de 2020.

RIBEIRO, Ronilda. [Iyakemi]. Alma africana no Brasil. Os iorubás.Sumaré (São Paulo): Editora Odudwa, 1996.

SÀLÁMİ, Síkírù [King]; RIBEIRO, Ronilda. I. Exu e a ordem do universo. São Paulo: Editora Oduduwa, 2011.

SOARES, João. Mulheres e negros são os mais afetados pela covid-19 no Brasil, aponta IBGE. Deutsche Welle Brasil. Berlim, 24 de julho de 2020. Disponível em: https://www.dw.com/pt-br/mulheres-e-negros-s\%C3\%A3o-os-mais-afetados-pe la-covid-19-no-brasil-aponta-ibge/a-54303900. Acesso em 30 de setembro de 2020

TV BAHIA. Cortejo com imagem de Omolu sai por ruas de Salvador para pedir saúde durante pandemia da Covid-19: 'Senhor da Cura'. O Globo. Rio de Janeiro, 1 de junho de 2020. Disponivel em: https://g1.globo.com/ba/bahia/noticia/2020 /06/01/cortejo-com-imagem-deomolu-sai-por-ruas-de-salvador-para-pedir-sau de-durante-pandemia-da-covid19-senhor-da-cura.ghtml. Acesso em 30 de setembro de 2020.

\footnotetext{
1 A RENAFRO Saúde, criada em 2003 a partir da colaboração de adeptos das religiões afrobrasileiras, gestores e profissionais da saúde, pesquisadores e lideranças do Movimento Negro, tem, dentre seus objetivos, estimular práticas de promoção da saúde, valorizar e potencializar o saber dos terreiros em relação à saúde, monitorar e intervir nas políticas públicas de saúde; estimular a relação entre as práticas de saúde realizadas nos terreiros e aquelas do SUS.

2https:/ / www.facebook.com/Afrobras-Federa\%C3\%A7\%C3\%A3o-das-Religi\%C3\%B5es-AfroBrasileiras-390649827621964/. Acesso em 22 de maio de 2020.

3https://www.facebook.com/renafrosaudeoficial/photos/a.1024573947694780/15724321762422 85/?type=3\&theater Acesso em 25 de maio de 2020.

${ }^{4}$ Mulher responsável de cuidar do terreiro.

5https://www.facebook.com/renafrosaudeoficial/ Acesso em 22 de maio de 2020.

6Ver, por exemplo, https://www.dw.com/pt-br/mulheres-e-negros-s\%C3\%A3o-os-mais-afetadospela-covid-19-no-brasil-aponta-ibge/a-54303900 e https://www.bbc.com/portuguese/brasil53338421 Acessos em 30 de setembro de 2020. Ver também Calvo (2020).

7 https://www.bbc.com/portuguese/brasil-52717493. Acesso em 15/02/2021.

${ }^{8}$ www.fonsanpotma.com.br. Acesso em 15 de fevereiro de 2021.
} 
9https://www.facebook.com/terreirotumbajunsara/photos/a.1141076949364593/168959781784 $5834 /$ ?type=3\&theater Acesso em 15 de maio de 2020.

10https://www.correio24horas.com.br/noticia/nid/em-isolamento-devotos-do-candomble-evocamorixa-

dacu-

ra/?utm_source=correio24h_share_facebook\&fbclid=IwAR1BALjLAQUgw9OOPDRWYDXHLbyKxWYI Z1rSk3EyRQFNWE5XLdat_bGvLo8. Acesso em 13de maio de 2020.

11 Pipoca, oferenda de Omolou, que tem a finalidade de purificar de todas as doenças e trazer a saúde.

12https://www.nordesteusou.com.br/noticias/imagem-de-omolu-ganha-as-ruas-de-salvador-emclamor-por-cura-e-saude-diante-da-covid-19/ Acesso em 30/09/2020.

13https://g1.globo.com/ba/bahia/noticia/2020/06/01/cortejo-com-imagem-de-omolu-sai-porruas-de-salvador-para-pedir-saude-durante-pandemia-da-covid-19-senhor-da-cura.ghtml. Acesso em 30 de setembro de 2020.

14https:/ /oglobo.globo.com/cultura/mae-de-santo-wanda-domolu-afirma-essa-doenca-vaidemorar-muito-passar-1-24359233 Acesso em 13 de maio de 2020.

15https://www.facebook.com/casadeoxumare/ Acesso em 25/06/2020.

16https://www.facebook.com/casadeoxumare/ Acesso em 12/05/2020.

17https://www.facebook.com/nilce.naira Acesso em 25/05/2020.

18 Como, por exemplo, o Instituto de Defesa dos Direitos das Religiões Afro-Brasileiras (IDAFRO).

19 No candomblé, é fundamental que, ao morrer, a pessoa seja enterrada. A possibilidade de que o grande número de mortes por Covid-19 leve à lotação dos cemitérios e à cremação dos cadáveres suscitou grande preocupação entre o povo de santo. Ver: https://www.correio24horas.com.br/noticia/nid/associacao-pede-proibicao-de-cremacaodeseguidores-do-

candom-

ble/?utm_source=correio24h_share_facebook\&fbclid=IwAR0PB9V_s6zIOgtJD2GrYQkAmp_KVzyl_K OxMjP2bghhadYkj2kddts9zTcAcesso em 11 de maio de 2020.

20https:/ / blogdaboitempo.com.br/2020/03/20/judith-butler-sobre-o-covid-19-o-capitalismo-temseus-limites / ?fbclid=IwAR3sKyOxuFi6RMXYO-KKvMvt_smG0CY4L3gut9xCRidADRU80Dw6UuYx9w Acesso em 07/05/2020.

${ }^{21}$ Como, por exemplo, Bruno Latour, Philippe Descola, Achille Mbembe, Thomas E. Lovejoy, Ailton Krenak, Greenpeace, the Intergovernmental Science-Policy Platform on Biodiversity and Ecosystem Services (IPBES), WWF International.

22https://www.correio24horas.com.br/noticia/nid/em-isolamento-devotos-do-candomble-evocamorixa-da-

cu-

ra/?utm_source=correio24h_share_facebook\&fbclid=IwAR1BALjLAQUgw9OOPDRWYDXHLbyKxWYI Z1rSk3EyRQFNWE5XLdat_bGvLo8 Acesso em 13 de maio de 2020.

23https://www.facebook.com/casadeoxumare/. Acesso em 12 de maio de 2020.

${ }^{24}$ Entendendo, por não-humanos, não somente coisas e seres naturais, mas também seres espirituais e "forças".

25 Muitos terreiros estão localizados nas periferias das grandes cidades, onde há uma situação socioeconômica precária.

Recebido em 30/09/2020

Aceito para publicação em 21/01/2021 